\title{
Mendeley Impact on Scientific Writing: Thematic Analysis
}

\author{
Kisman Salija\#, Rahmat Hidayat*, Andi Anto Patak ${ }^{\#}$ \\ \# English Department, Faculty of Languages and Literature, Universitas Negeri Makassar, Makassar, South Sulawesi, Indonesia \\ E-mail: ${ }^{1}$ kismansalija@unm.ac.id; ${ }^{3}$ andiantopatak@unm.ac.id
}

*Department of Information Technology, Politeknik Negeri Padang, Padang, Sumatera Barat, Indonesia

E-mail: rahmat@polinpdg.ac.id

\begin{abstract}
The quality of scientific writing is based on its impact on knowledge development. This study aims at exposing the Mendeley impact on scientific writing. The thematic analysis was applied in this study to transcribe the recordings and translate as well as analyze the transcripts through NVivo 8 software. This study reveals that the identified themes appeared in this study are avoiding plagiarism, backup file, change citation style, personal library, and social network. This study recommends that due to the plagiarism deterrent is problematic in scientific writing; students are required to be educated on this issue. This study also reveals that research collaboration in internet connection could be the basis of building the real network by creating research community and organizing conference for knowledge sharing among the researchers.
\end{abstract}

Keywords - Mendeley, scientific writing, research impact, thematic analysis.

\section{INTRODUCTION}

Understanding on good scientific writing determines the career of a researcher. The scientific work written by researcher should have a significant impact on knowledge development [1]. Therefore, researcher is encouraged to get published in accredited national journal or reputable International journal. However, many researchers have poor awareness of high impact work; hence they are less intensive to produce scientific paper. Therefore, the researcher should be smart-working in conducting research to produce quality scientific work. The quality and technique of writing scientific papers are determined by the originality [2]. That is, the scientific work is the original work of the researcher. Similarities among the scientific work could happen; however; it does not mean ignoring the originality or authenticity.

University, the main producer of a researcher, has an abundant responsibility to provide education and outreach related to the plagiarism prevention [3]. Plagiarism might trap researcher for rapid publication rather than carry out research findings honestly [4]. This, of course, needs to be our concern; therefore plagiarism concept becomes one of the important issues agreed by students and professors to avoid plagiarism. Crediting other work is an indication of respecting other author ideas [5], [6]. We all know that knowledge is developed based on the knowledge that already exists. By citing other work, the researcher could be self- confident avoiding plagiarism when preparing scientific papers to show an academic honesty that enriches our papers. Citing, referencing, and quoting describe clearly, which part of our writing and which part of other ideas we refer.

Therefore, a strong argument in scientific must be based on related references to avoid plagiarism [7]. The author has to mention the citation and quotation in text as well as references to all sources. Many researchers might claim that they cite appropriately other work, but in fact, they did it inappropriately due to the lack of citation insight [8]. The citation must be made using a particular style known as citation style, but this is always difficult for students to master [9]. The citation is used in scientific works to provide credit or recognition of the influence of the earlier work, or refer to who has the authority of the findings. Citation allows the reader to assess what is being currently found based on previous work. The authors are often directly involved in these findings and to explain why they agree or disagree with the previous research results. However, at the time of completing the paper writing or scientific work, often bothers researcher in the preparation of creating a bibliography.

The convenience offered by Mendeley allowing a researcher to be assured in creating the bibliography and the citation of an online journal article [10]-[12]. Many researchers consider that the use of online journals is very helpful and make it easier to support the activities of research. However, if the online journal articles that have 
been downloaded are not documented correctly, it will be very tough to research when necessary. The journal articles online are definitely accessible in a good library database management. However, the lack of human resource on database management software makes the library database is in poor management. One application database that can be used to manage online journal articles is Mendeley. In fact, many database applications are available, Mendeley provides free access and can be used to manage the library either in individual or institution. However, such applications often cause librarians be difficult to make a references selection that will be integrated into the campus library. However, Mendeley provides the easiest method integrating Mendeley to the campus library software by subscribing Mendeley Institutional Edition [13]. Mendeley facilitates researcher to create citations and references. It is widely used by researchers and academician, professional author to cite sources, especially from the journal, especially for students who are writing theses and dissertations. Many universities in various countries required the use of citation and reference manager in writing thesis and dissertation. Mendeley is also a program-based desktop, and the web is used for managing and sharing research papers, find the research data and collaborating online [14]-[16]. The program combines the Desktop, PDF and reference management application that is available for Windows operating systems, Mac and Linux. Nowadays, many Mendeley users tend to rely their reference management on Mendeley mobile [15].

For a researcher, the ease of making the bibliography, especially for synchronizing thousands of references leading to feeling the positive emotion from the threat of plagiarism. Besides, Mendeley can help saving time in searching and viewing the full-text document in PDF view on Mendeley Desktop. All the documents in Mendeley Desktop are the offline backup that can work well with word processing plugin for automatic citation and reference. Aside from being a citation and reference manager that certainly is individualized, Mendeley also supports the collaborative research. The collaboration is supported by Mendeley Web that provides a means to be interconnected discussing current issues, sharing knowledge, even the sharing of reading material in one group collaboration [14], [16]-[18]. However, the growing use of Mendeley due to its feature integrating citation manager and social media [19]. By all these features own by Mendeley, the researchers were interested in investigating them through the interview the Indonesian Mendeley users to reveal the current impact of Mendeley in scientific writing.

\section{METHOD}

Ten Indonesian Mendeley users participated as the interviewee in this study. The interview is based on the impact of Mendeley in scientific writing. The researchers transcribed the recordings and translated as well as analyzed the transcripts through NVivo 8 software using thematic analysis. In a qualitative study, by thematic analysis as the most popular approach data analysis, the researchers could investigate the response of interviewee [20], [21]. Thematic analysis leads the study to focus on the importance of intended and well-organized description data on the documents or recording format. Identified theme and subtheme are presented and summarized in this study based on the results of the interview. The researchers assigned the consistent code for interviewee to ensure the confidential interviewee's identity. In this study, theme and subtheme signify response level of the interviewee in a dataset.

The thematic analysis simplifies the words, phrases, and sentences to be vibrant ideas credentials. This study performed thematic analysis during the process of coding based on six phases as in Braun and Clarke [20] to mark accepted arrangements. These phases are data familiarizing, initial codes generating, theme searching, theme reviewing, theme defining and naming, and report producing. However, coding is the furthermost vital process to arrange theme and subtheme to encode the familiar, essential moments before interpreting the raw data.

\section{RESULTS}

This section presents the summary of distinct theme and subtheme extracted from the interview results. The themes identified in this study are avoiding plagiarism, backup files, change citation style, personal library, and social network. The detail of theme and subthemes are presented and discussed as follows.

\section{A. Avoiding Plagiarism}

Mendeley user in this study talked that Mendeley is a helpful tool for students, books author, and researcher in avoiding plagiarism. Mendeley feature on synchronizing bibliography and citation is considerably existent to avoid plagiarism. In addition, the Mendeley user also experienced that Mendeley helps researcher avoiding plagiarism through the ability of Mendeley in managing previous findings. However, students need training on how to cite and reference properly to avoid plagiarism [22]. Figure 1 below describes the theme of avoiding plagiarism and two related subthemes.

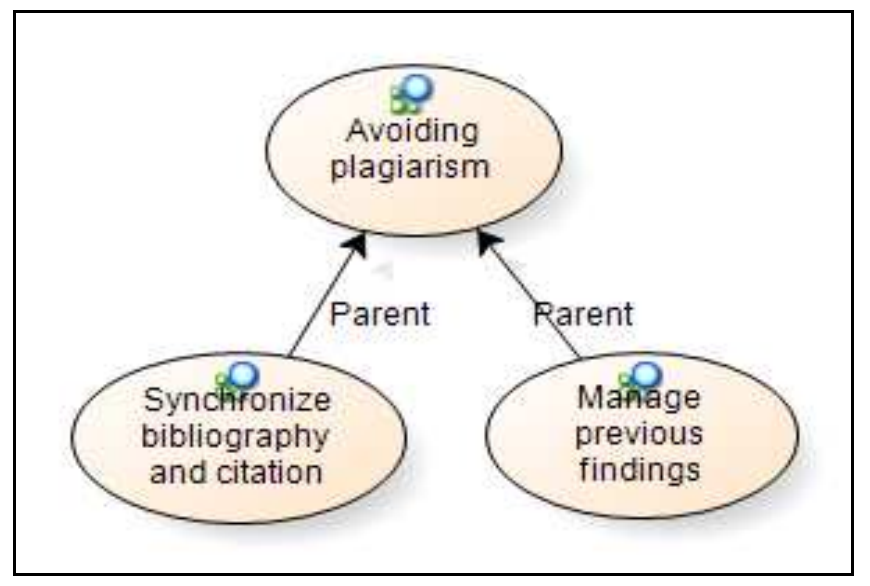

Fig. 1 Theme of "Avoiding plagiarism" and sub theme

Figure 1 above indicates that "Avoiding plagiarism" theme consists of "synchronize bibliography and citation" and "manage previous findings" subthemes. The detailed of these subthemes are described and discussed in the following section. 
(1) Synchronize Bibliography and Citation: The interviewee 1 in this study reported that "In academic writing, listing bibliography based on the citation in a thesis, dissertation, journals, and books is mandatory to avoid plagiarism." Mendeley user exposed experience that listing the correct bibliography is required in avoiding plagiarism. This expose supported by Interviewee 4 who talked that "Mendeley works well with word processing to create citations and bibliographies automatically, minimize citation mistake, and prevents the accidental plagiarism." Mendeley users were experiencing that Mendeley is compatible with word processing software in creating automatic citation and bibliography to minimize inappropriate citation and avoid plagiarism. This experience was supported by Interviewee 5 who communicated that: "Mendeley creates citation and bibliography automatically to minimize the plagiarism." Thus, Mendeley users were experiencing the synchronize between citation and references, or bibliography is an attempt to avoid plagiarism in academic or professional writing.

2) Manage Previous Findings: Interviewee 1 spoke that "Bibliography must be complete and suitable to citation style as a guideline for authors and retrieve all the related previous findings." This statement indicates the strong principle of Mendeley user in detecting the previous findings to create a novelty as one of the efforts in avoiding plagiarism.

However, both of subthemes above are feature, provided by Mendeley, which are noticeably suitable to avoid plagiarism. Indeed, in scientific writing, avoiding plagiarism is easy in concept, but difficult to practice [23]. Thus, avoiding plagiarism need more training to find out the proper strategy.

\section{B. Backup Files}

The respondents in this study described the significance of "Backup File" Mendeley feature, especially for the librarian. Mendeley users reported that "Backup File" feature is supported by XML export to save full-text PDF file in local drive. Backup is subject to cut down the reliance on the internet connection. Figure 2 below shows the theme of "Backup File" including two subthemes.

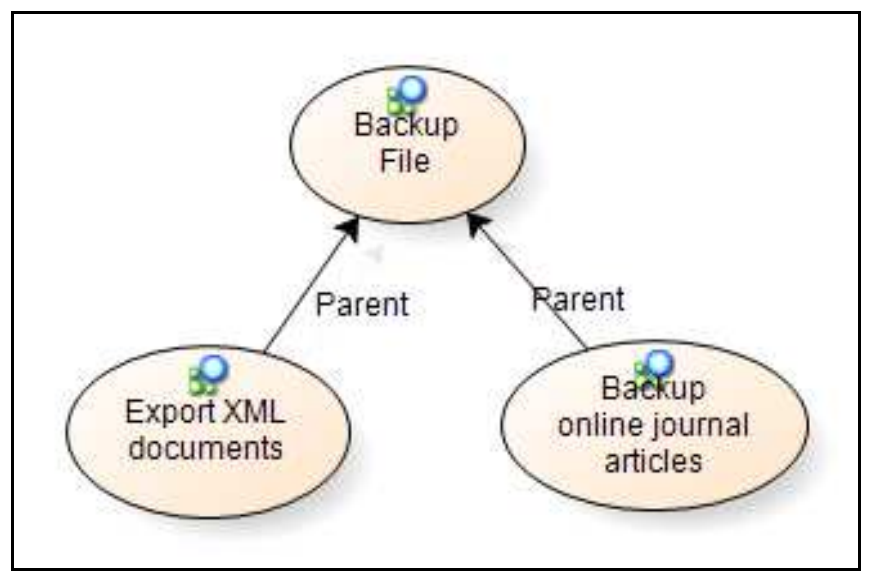

Fig. 2 Theme of "Backup File" and subtheme

Figure 2 above categorized subtheme of "export XML documents" and "backup online journal" attributed to theme of "Backup File." In the following section, the subtheme of "Backup File' is described.

1) Export XML Documents: Interviewee 3 expressed suggestion in this study that "The information technology team can work together with librarian to export billion fulltext documents using XML feature." This suggestion is addressed to the Information Technology (IT) team and the librarian to work together exporting the XML documents. Although this feature is accessible in personal computer, the Mendeley users suggested exporting massively the PDF fulltext in the university library database.

2) Backup Online Journal Articles: Interviewee 3 revealed that "Mendeley application could also be used to manage online journal articles by librarians as a backup file of journals subscribed by the institution." This study revealed that Mendeley user recommends librarians to backup online journal articles. Backup is anticipation to the offline internet connection to keep accessing the documents in library although internet connection is offline. Similarly, Interviewee 10 experienced that "Mendeley can facilitate user to manage the downloaded articles offline to diminish the dependence on the internet connection." It seems that Mendeley users in this study described their experience in using Mendeley Institutional Edition (MIE) where a librarian has access on Mendeley access through the university library. In addition, librarian also can back up the metadata in good backup process [24]. However, the fact growing development of mobile makes Mendeley user synchronize their article on cloud computing through pocket mobile [15].

\section{Change Citation Style}

Mendeley users shared their personal experience using Mendeley in writing the journal article. This study revealed positive talk by Mendeley users that Mendeley is worthwhile in changing citation style. It seems that Mendeley users experienced writing different articles on one device or computer. Figure 3 below shows the theme of "Change citation style" consists of two subthemes as follows.

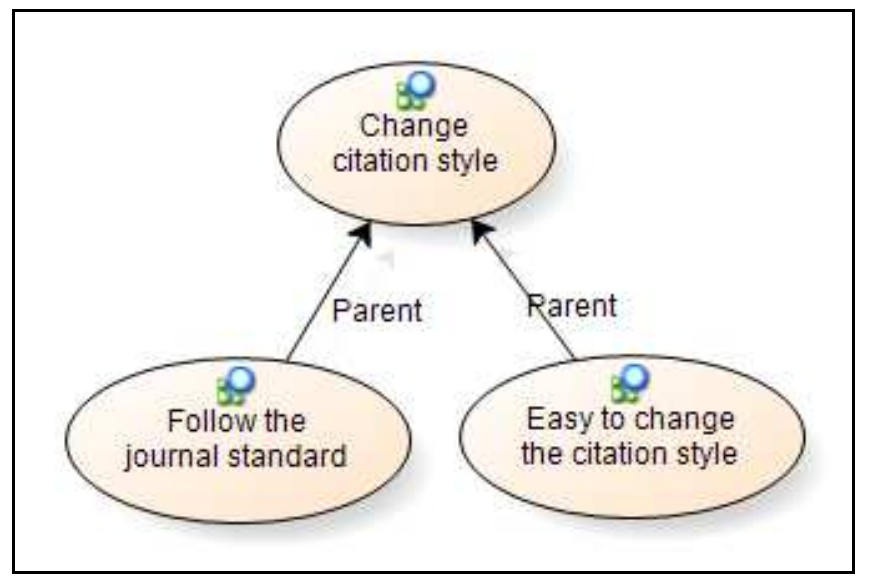

Fig. 3 Theme of "Change the citation style"

Figure 3 above shows theme of "Change citation style" is associated with subthemes of "Follow journal standard" and "Easy to change the citation style." The details of these subthemes are as follows. 
1) Follow the Journal Standard: Interviewee 8 stated that "We can extract bibliography format following the standard that we can choose." It seems that Mendeley users were confused in using the term of "extract bibliography format." In fact, bibliography or references format depend on the citation style that includes the format of references. Indeed, this feature enables Mendeley users to change the citation style in MS Word plugin based on the journal or any publication target style.

2) Easy to Change the Citation Style: Mendeley users reported the positive excitement using Mendeley for automatic citation. This encouraging feeling showed by Interviewee 1 that "if the citation style changes, the author find easiness to change the bibliographic style one by one as well, especially for submitting an article to certain citation style." Meanwhile, Interviewee 7 responded the Mendeley impact interview that "Mendeley provides many citation styles, including APA, IEEE, and other styles enables me to be used to manage journal article using Mendeley and cite them through MS Word." Thus, Mendeley users experienced the availability of many citation styles in Mendeley is helpful to convert the citation based on any journal citation style. Easy to change the citation style meets the accessibility principle on software citations that should enable access to the software itself as well as to its related metadata, documents, data, and other necessary material [25].

\section{Personal Library}

The main characteristic of research is how to create a private research library, reach and retrieve references anytime for accurate and comprehensive citation [26]. Figure 4 below indicates theme of "Personal library" consists of three subthemes, they are "Highlight documents," "Create Library," and "Create database of references." The explanation of these three subthemes is provided in the following section.

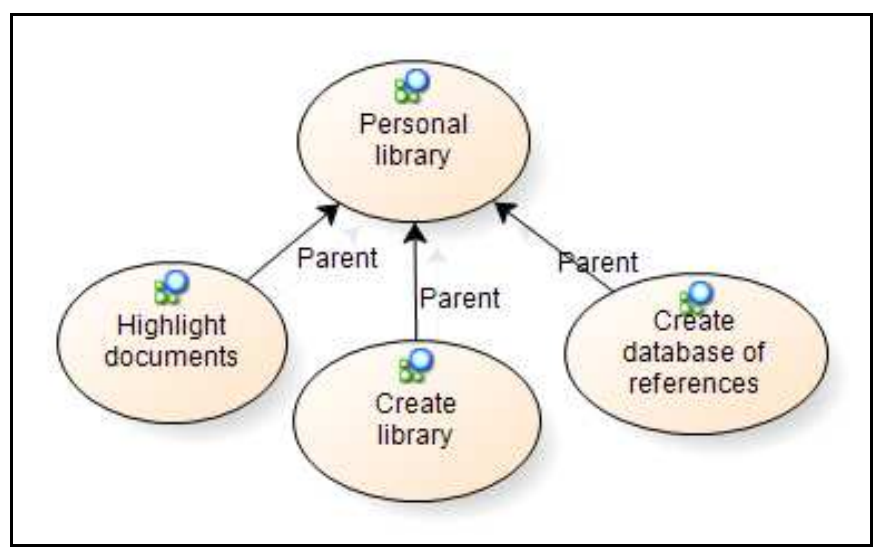

Fig. 4 Theme and subthemes of "Personal library"

Based on the Figure 4 above the researchers provide the details of subthemes linked to theme of "Personal library" as in the following part.

1) Highlight Documents: Interviewee 9 spoke that "Mendeley is also useful to store downloaded PDF files marked by notes and highlights." It seemed from the interview that Mendeley users were getting familiar with notes and highlights feature on PDF full-text in their personal library
2) Create Library: Mendeley users were experiencing of the significance of using Mendeley is creating personal library. Interviewee 4 revealed that "MendeIey can create a library contains the files of the journal, books, reports, and other references format." Similarly, Interviewee 9 also reported that "Mendeley functions as a personal library partner of word processing."

3) Create Database of References: It is revealed from this study that Mendeley users consider using Mendeley as an application for creating the database of references. This reveal is supported by Interviewee 4 report that "Mendeley, is a program to create a database of references and use them for the scientific writing." This report is supported by Interviewee 5 statement that "In my opinion, Mendeley is a software application that has a function in processing scientific databases such as e-journals, e-books, records, bibliography, or other references that support a scientific database."

\section{E. Social Network}

Figure 5 below exposes the unique feature of using Mendeley; it is "Social network." This study described that Mendeley users used this feature through web and mobile as well as building a real community through research association. This characteristic is reasonably different from other social network because collaboration using Mendeley is dominantly private. However, Mendeley allows another computer to automatically extract informative public data of frequently viewed papers [19].

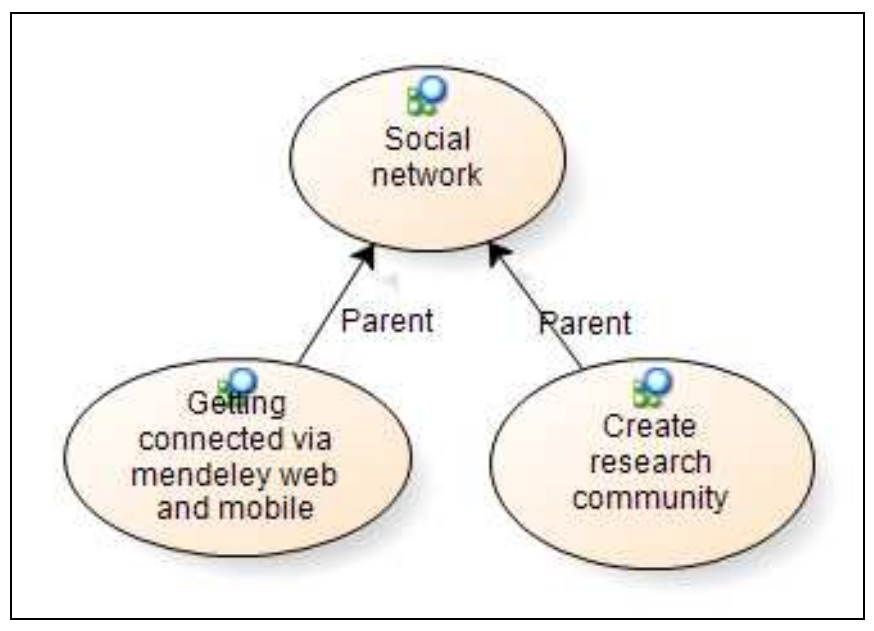

Fig. 5 Theme of social network

The following description of "Getting connected via Mendeley web and mobile" and "research association community" subthemes based on the figure 5 above.

1) Getting Connected via Mendeley Web and Mobile: Interviewee 9 reported that "Mendeley Web or Mendeley Mobile as well as to get connected to research network through Mendeley Web and Mobile." Mendeley users seemed to be interested in this social network feature for online media to discuss with other researcher dealing with the literature as a concern of the current research.

2) Create Research Community: Mendeley users also experienced that Mendeley is not only helpful as the citation manager, but also as media for discussion to promote knowledge sharing. This supported by the exposing of 
Interviewee 10 describing that "For scholars, this application is very helpful in making the citation, bibliography as well as creating research association community for knowledge sharing."

\section{IV.DISCUSSION}

This study investigates five identified themes and nine subthemes. Mendeley users reported different experience using Mendeley as the impact in scientific writing. By overall responses from the interview, this study categorizes the Mendeley impact in five parts; they are avoiding plagiarism, backup file, change citation style, personal library, and social network.

This study exposes that Mendeley is a supportive instrument for student and professional author to avoid plagiarism. Plagiarism deterrent is the most challenging for scientific writing [23]. By synchronizing bibliography and citation, this study is considerably popular to evade plagiarism. This study also reveals that managing previous findings in Mendeley Desktop enable author identifying and mapping all the related findings related to the working paper to avoid reduplicate the previous publication. Plagiarism is severe problem required special attention by stakeholders. This circumstance necessitates evaluation in instruction to reduce or avoid the plagiarism [27]. Avoiding plagiarism in scientific writing is problematic [23].Therefore, students need much extra training on citing and referencing properly to avoid plagiarism [22].

Mendeley users also described the impact of saving the file in local drive or library database by the librarian as backup to ease the dependency on the internet connection inside campus proxy area. The Indonesian Mendeley users seem to be worried on the internet connection as they revealed the importance of saving or protecting the file in a local drive by library members and local host by the librarian. By using Mendeley, the backup file is no longer difficult to organize [28]. The backup cold be in cloud computing using pocket mobile [15]. Mendeley users reported their experience using the Mendeley Institutional Edition (MIE) to delegate the librarian creating backup the file for continuous access although the internet is in low connection or even offline.

This study publicizes encouraging information flow by Mendeley users on the ease of changing citation style especially for writing more than one article on one computer. Journal has different citation style require researcher is accustomed to many kinds of citation. Mendeley provides all the citation style to use in scientific writing based on the journal target for publication plan [29]-[31]. Mendeley enables the user to change quickly the citation format from one journal to another type and or target of publication.

Mendeley users also spoke that they were experiencing to highlight documents and create references database in Mendeley as the personal library. Indeed, this database is very helpful in conducting research, especially for detecting all the related references on an issue to study. All the references that we have managed in one device could be accessed in another computer using our personal Mendeley login. Thus, Mendeley is personal online library, which is accessible anytime, anywhere, and even any device as well as help a researcher conducting research and providing the database of dynamic research of allocation using other tools and strategy [32].

Ultimately, Mendeley users exposed their interest using Mendeley due to the existence of social network that encourages them to be connected either on the internet or in the real community interaction through a research association conference. This study reveals that the social network characteristic built online through the internet is the basis of creating real network by attending conference on the research community. This is the unique of Mendeley, which is different from other social media due to its collaboration is on research especially for detecting another researcher who viewed certain papers [19].

\section{CONCLUSION}

Five identified themes, and nine subthemes were identified in this study based on the reports of Mendeley users on Mendeley impact on scientific writing. Data of this study were collected through the interview. The analysis data was done through Nvivo 8 software using thematic analysis. This study revealed that Mendeley impact in scientific writing is divided into five themes, they are "avoiding plagiarism," "backup file," "change citation style," "personal library," and "social network". "Avoiding plagiarism" theme consists of two subthemes, they are "synchronize bibliography and citation" and "manage previous findings." This study exposed that Mendeley is a helpful tool for the author to avoid plagiarism. The second theme is "backup file" including "export XML documents" and "backup online journal articles". This study described the power of saving the file in local personal drive or campus repository by the librarian to reduce the reliance on the internet connection. The next theme identified in this study is "change citation style" covering two subthemes; they are "follow the journal standard" and "easy to change the citation style." This study published inspiring information on the simplicity of the citation style. The fourth theme appeared in this study is "personal library" involving "highlight documents," "create library", and "create database of references" as subthemes. This study indicated that Mendeley users experienced using feature of highlighting documents and creating personal references database. Finally, this study exposed that "social network" has special position in the heart of Mendeley users. This theme consists of subtheme of "getting connected via Mendeley web and mobile" and "create research community." Lastly, this study exposed Mendeley users' concern using Mendeley to be globally connected either in internet or in real research community.

\section{REFERENCES}

[1] Y.-N. Lee, J. P. Walsh, and J. Wang, "Creativity in scientific teams: Unpacking novelty and impact," Res. Policy, vol. 44, no. 3, pp. 684697, Apr. 2015.

[2] D. Alderson, "How to critically appraise a research paper," Paediatr. Child Health (Oxford)., vol. 26, no. 3, pp. 110-113, Mar. 2016.

[3] A. Stuhmcke, T. Booth, and J. Wangmann, "The illusory dichotomy of plagiarism," Assess. Eval. High. Educ., vol. 41, no. 7, pp. 982-995, Oct. 2016.

[4] H. Sabir, S. Kumbhare, A. Parate, R. Kumar, and S. Das, "Scientific misconduct: a perspective from India," Med. Heal. Care Philos., vol. 18, no. 2, pp. 177-184, May 2015. 
[5] J. M. Stephens, "Creating Cultures of Integrity: A Multi-level Intervention Model for Promoting Academic Honesty," in Handbook of Academic Integrity, Singapore: Springer Singapore, 2015, pp. 110 .

[6] T. S. Manly, L. N. K. Leonard, and C. K. Riemenschneider, "Academic Integrity in the Information Age: Virtues of Respect and Responsibility," J. Bus. Ethics, vol. 127, no. 3, pp. 579-590, Mar. 2015.

[7] D. Pecorari, "Plagiarism, International Students and the SecondLanguage Writer," in Handbook of Academic Integrity, Singapore: Springer Singapore, 2015, pp. 1-11.

[8] B. G. Ekelund, "Citing the world: A geometric data analysis of Swedish literary scholars' use of foreign critical resources," Poetics, vol. 55, pp. 60-75, Apr. 2016.

[9] S. Lanning, "A modern, simplified citation style and student response," Ref. Serv. Rev., vol. 44, no. 1, pp. 21-37, Feb. 2016.

[10] V. Henning and J. Reichelt, "Mendeley-A Last. fm for research?," in eScience, 2008. eScience'08. IEEE Fourth International Conference on, 2008, pp. 327-328.

[11] A. A. Patak, H. A. Naim, and R. Hidayat, "Taking Mendeley as Multimedia-based Application in Academic Writing," Int. J. Adv. Sci. Eng. Inf. Technol., vol. 6, no. 4, p. 557, Aug. 2016.

[12] M. Basri and A. A. Patak, "Exploring Indonesian students' perception on Mendeley Reference Management Software in academic writing," in 2015 2nd International Conference on Information Technology, Computer, and Electrical Engineering (ICITACEE), 2015, pp. 8-13.

[13] F. Galligan and S. Dyas-Correia, "Altmetrics: Rethinking the way we measure," Ser. Rev., vol. 39, no. 1, pp. 56-61, 2013.

[14] W. Jeng, D. He, and J. Jiang, "User participation in an academic social networking service: A survey of open group users on Mendeley," J. Assoc. Inf. Sci. Technol., vol. 66, no. 5, pp. 890-904, 2015.

[15] J. Shin, "Mendeley Mobile: Powerful Cloud-Based Article and Reference Management in Your Pocket," J. Digit. Imaging, pp. 1-3, 2016.

[16] P. Sud and M. Thelwall, "Not all international collaboration is beneficial: The Mendeley readership and citation impact of biochemical research collaboration," J. Assoc. Inf. Sci. Technol., 2015.

[17] H. Zaugg, R. E. West, I. Tateishi, and D. L. Randall, "Mendeley: Creating communities of scholarly inquiry through research collaboration," TechTrends, vol. 55, no. 1, pp. 32-36, 2011.
[18] K. Ma, A. Abraham, B. Yang, and R. Sun, "Intelligent Web Data Management of Literature Sharing," 2016, pp. 147-162.

[19] R. Van Noorden, "Online collaboration: Scientists and the social network," Nature, vol. 512, no. 7513, pp. 126-129, Aug. 2014.

[20] V. Braun and V. Clarke, "Using thematic analysis in psychology," Qual. Res. Psychol., vol. 3, no. May 2015, pp. 77-101, 2006.

[21] G. Guest, K. M. MacQueen, and E. E. Namey, Applied thematic analysis. Sage, 2011.

[22] J. Gunnarsson, W. J. Kulesza, and A. Pettersson, "Teaching International Students How to Avoid Plagiarism: Librarians and Faculty in Collaboration," J. Acad. Librariansh., vol. 40, no. 3-4, pp. 413-417, May 2014.

[23] E. R. Fisher and K. M. Partin, "The Challenges for Scientists in Avoiding Plagiarism," Account. Res., vol. 21, no. 6, pp. 353-365, Nov. 2014.

[24] M. Hebbar, V. Khanduja, K. Bachu, and S. Ramachandran, "Method and system for enhanced backup database indexing." Google Patents, 04-Oct-2016.

[25] A. M. Smith, D. S. Katz, and K. E. Niemeyer, "Software citation principles," PeerJ Comput. Sci., vol. 2, p. e86, 2016.

[26] P. Dunleavy, "Organizing your personal research library and compiling bibliographies: I was an EndNote refusenik, but now I'ma Mendeley convert," Impact Soc. Sci. Blog, 2012.

[27] N. Kashian, S. M. Cruz, J. Jang, and K. J. Silk, "Evaluation of an Instructional Activity to Reduce Plagiarism in the Communication Classroom," J. Acad. Ethics, vol. 13, no. 3, pp. 239-258, 2015.

[28] P. Bhargava, S. Dhand, A. E. Lackey, T. Pandey, M. Moshiri, and K. Jambhekar, "Radiology Education 2.0-On the Cusp of Change. Part 2. eBooks; File Sharing and Synchronization Tools; Websites/Teaching Files; Reference Management Tools and Note Taking Applications.," Acad. Radiol., vol. 20, no. 3, pp. 373-381, 2013.

[29] J. Kratochvíl, "Comparison of the Accuracy of Bibliographical References Generated for Medical Citation Styles by EndNote, Mendeley, RefWorks and Zotero," J. Acad. Librariansh., 2016.

[30] R. Nariani and Y. Ithayakumar, "Learning Mendeley through Certification Program for Librarians," 2015.

[31] M. O. Sungur and T. Ö. Seyhan, "Writing references and using citation management software," Turkish J. Urol., vol. 39, no. Suppl 1, p. 25, 2013.

[32] A. Wolke, M. Bichler, F. Chirigati, and V. Steeves, "Reproducible experiments on dynamic resource allocation in cloud data centers," Inf. Syst., vol. 59, pp. 98-101, Jul. 2016. 